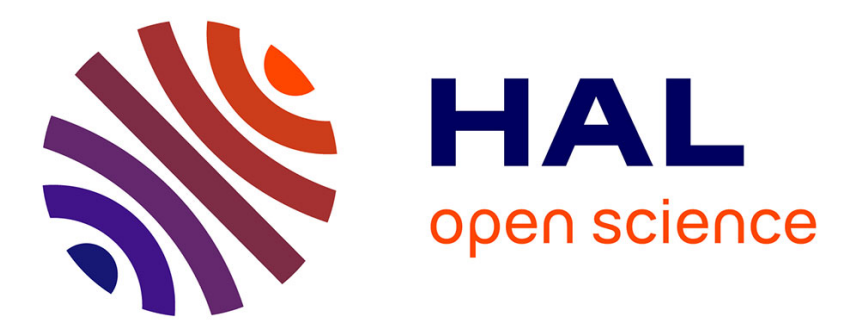

\title{
A theoretical and experimental study of non-linear absorption properties of substituted 2,5-di-(phenylethynyl)thiophenes and structurally related compounds.
}

Per Lind, Marcus Carlsson, Bertil Eliasson, Eirik Glimsdal, Mikael Lindgren, Cesar Lopes, Linus Boman, Patrick Boman

\section{To cite this version:}

Per Lind, Marcus Carlsson, Bertil Eliasson, Eirik Glimsdal, Mikael Lindgren, et al.. A theoretical and experimental study of non-linear absorption properties of substituted 2,5-di(phenylethynyl)thiophenes and structurally related compounds.. Molecular Physics, 2009, 107 (07), pp.629-641. 10.1080/00268970902845289 . hal-00513267

\section{HAL Id: hal-00513267 https://hal.science/hal-00513267}

Submitted on 1 Sep 2010

HAL is a multi-disciplinary open access archive for the deposit and dissemination of scientific research documents, whether they are published or not. The documents may come from teaching and research institutions in France or abroad, or from public or private research centers.
L'archive ouverte pluridisciplinaire HAL, est destinée au dépôt et à la diffusion de documents scientifiques de niveau recherche, publiés ou non, émanant des établissements d'enseignement et de recherche français ou étrangers, des laboratoires publics ou privés. 


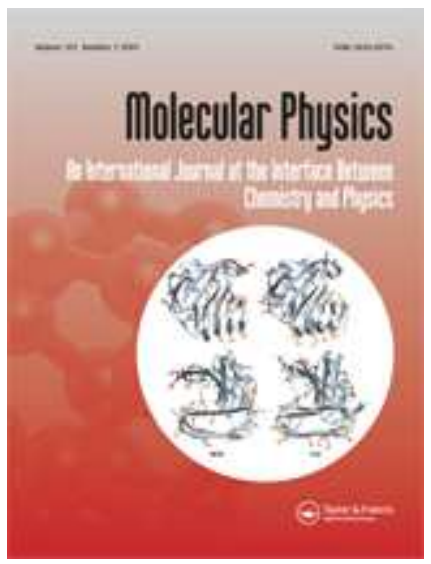

\section{A theoretical and experimental study of non-linear absorption properties of substituted 2,5-di- (phenylethynyl)thiophenes and structurally related compounds.}

\begin{tabular}{|c|c|}
\hline Journal: & Molecular Physics \\
\hline Manuscript ID: & TMPH-2008-0296.R1 \\
\hline Manuscript Type: & Full Paper \\
\hline $\begin{array}{l}\text { Date Submitted by the } \\
\text { Author: }\end{array}$ & 19-Feb-2009 \\
\hline Complete List of Authors: & $\begin{array}{l}\text { Lind, Per; NBC Defence, FOI } \\
\text { Carlsson, Marcus; Department of Chemistry } \\
\text { Eliasson, Bertil; Department of Chemistry } \\
\text { Glimsdal, Eirik; Department of Physics } \\
\text { Lindgren, Mikael; Department of Physics } \\
\text { Lopes, Cesar; Division of Sensor Technology } \\
\text { Boman, Linus; Department of Physics, Chemistry and Biology } \\
\text { Boman, Patrick; Department of Physics, Chemistry and Biology }\end{array}$ \\
\hline Keywords: & $\begin{array}{l}\text { Density functional theory, Two-photon absorption, Excited state } \\
\text { absorption, Optical limiting, Chalcogenophenes }\end{array}$ \\
\hline
\end{tabular}

\section{ScholaroNE" \\ Manuscript Central}




\title{
A theoretical and experimental study of non-linear absorption properties of substituted 2,5-di-(phenylethynyl)thiophenes and structurally related compounds
}

\author{
Per Lind ${ }^{\mathrm{a}, \mathrm{b}}$, Marcus Carlsson ${ }^{\mathrm{a}}$, Bertil Eliasson ${ }^{\mathrm{a}, \mathrm{i}}$, Eirik Glimsdal ${ }^{\mathrm{c}}$, Mikael Lindgren ${ }^{\text {b,c }}$, \\ Cesar Lopes ${ }^{\mathrm{d}}$, Linus Boman ${ }^{\mathrm{e}}$, Patrick Norman ${ }^{\mathrm{e}, \mathrm{i}}$ \\ a Department of Chemistry, Umeå University, SE-901 87 Umeå, Sweden \\ ${ }^{\mathrm{b}}$ NBC Defence, FOI, Cementvägen 20, SE-901 82 Umeå, Sweden \\ ' Department of Physics, Norwegian University of Science and Technology (NTNU), NO-7491 \\ Trondheim, Norway \\ d Division of Sensor Technology, Swedish Defence Research Agency (FOI), SE-581 11 Linköping, \\ Sweden \\ ${ }^{\mathrm{e}}$ Department of Physics, Chemistry and Biology, Linköping University, SE-581 83 Linköping, Sweden
}

Keywords: Density functional theory, Two-photon absorption, Excited state absorption, Optical limiting, Chalcogenophenes, Thiophenes, DFT, TPA

\begin{abstract}
Photo-physical properties relevant for optical power limiting in the near-visible and visible regions of the spectrum are reported for a series of substituted diarylalkynyl chalcogenophenes (furans, thiophenes, selenophenes, and tellurophenes). The linear ground and excited state absorption as well as the nonlinear two-photon absorption were determined at the time-dependent density functional theory level with use of the hybrid exchange-correlation functionals B3LYP and CAM-B3LYP. A selected number of the theoretically studied molecules were synthesized and characterized experimentally with the use of absorption and luminescence spectroscopy. The photo-physical data are compared to the results from optical power limiting measurements performed in THF solution at a wavelength of $532 \mathrm{~nm}$, with a laser pulse length of $5 \mathrm{~ns}$ and pulse energies
\end{abstract}

\footnotetext{
${ }^{i}$ Corresponding authors. E-mail address (Eliasson): bertil.eliasson@chem.umu.se, E-mail address (Norman): panor@ifm.liu.se.
} 
up to $150 \mu \mathrm{J}$. The best compounds in the present investigation display an energy damping of approximately a factor of 10 at a concentration of $0.010 \mathrm{M}$.

\section{Introduction}

The interest for third-order nonlinear optical (NLO) properties of organic materials has grown considerably during the last two decades due to the potential of finding inexpensive and easily processable materials for different optical applications including all-optical signal processing [1-7]. These applications can, for instance, take advantage of two-photon absorption/emission and third harmonic generation properties of the materials [7-9]. Our interest in this area involves nonlinear absorption as a means for protection of eyes and various types of sensors in optical equipment from laser beams operating at wavelengths in the visible region [6,10-12]. A primary requirement of the material is fast switching from high transparency for normal light (or low laser power) to non-transparency at high laser incident fluences. Such fast optical power limiting (OPL) may be obtained by the molecular process excited-state absorption (ESA), possibly in conjunction with two-photon absorption (TPA) which typically occurs only at high laser irradiance [6,7,10,13-15].

Many studies have shown that an extended molecular $\pi$-electron system is an important characteristic for achieving large NLO effects [7,16-18]. Among the large number of molecules, oligomers and polymers that have been investigated for NLO properties, it is common that benzenoid rings are present in the structures. Often, the aromatic rings are linked together via acetylene groups, and this appears to be a useful element in the design of NLO systems [16,19].

In earlier work on relatively small molecules with benzenoid rings and heteroatom-containing aromatic rings, we performed measurements of OPL at $532 \mathrm{~nm}$ [20-22]. It was found that 2,5-di(phenylethynyl) thiophenes and a corresponding furan gave interesting results. Moreover, such structures can easily be synthesized and their $\pi$ systems can be widely modified and extended by standard coupling reactions. Even though significantly better OPL properties were reported from studies of e.g. phthalocyanines and diarylalkynyl-bisphosphine Pt(II) complexes [12,23,24], thiophene compounds have other beneficial properties. The transparency in the visible range and 


\section{Figure 1 can be inserted here}

\section{Experimental and computational details}

\subsection{Quantum chemical calculations}

Structure optimizations of all molecules were performed with the Gaussian 03 program [25], at the DFT level of theory using the hybrid B3LYP [26] exchange-correlation functional and Dunning's correlation consistent cc-pVDZ basis set [27] for the H, C, N and $\mathrm{O}$ atoms and the Stuttgart effective core potentials (ECPs) [28] for S, Se and Te (using valence basis sets with polarizing $d$-functions). All molecular structures were optimized in the $C_{2 v}$ point group, with the $z$-axis being the principle axis and the $y$-axis being the conjugation axis. The three components of the electric-dipole operator $\left(\mu_{\mathrm{x}}, \mu_{\mathrm{y}}\right.$, and $\mu_{\mathrm{z}}$ ) thereby span the irreducible representations $B_{1}, B_{2}$, and $A_{1}$, respectively. The molecular property calculations were carried out with the Dalton program [29] at the time-dependent Hartree-Fock and DFT levels of theory. In addition to the use of the B3LYP functional we have also employed the Coulomb attenuated B3LYP (CAMB3LYP) [30] functional in order to obtain a correct asymptotic Coulomb interaction between the hole and electron orbitals in the excitation processes. This version of the Dalton program includes an implementation of the CAM-B3LYP functional by Peach et al. [31]. 
The all-electron basis sets used in the property calculations are based on the standard 6-31G basis set [32] and the cc-pVDZ and cc-pVTZ basis sets of Dunning [27], but additional diffuse and polarization functions have been added as stated in the text and tables.

The one-photon transition moments describing the ground state linear absorption were obtained from the first-order residue of the electric-dipole polarizability, whereas those describing excited state absorption were obtained from the second-order residue of the first-order hyperpolarizability. The two-photon transition moments were identified from the first-order residue of the hyperpolarizability. A detailed presentation of the relations between linear and nonlinear response functions and the one- and twophoton transition moments is found in the work of Norman and Ruud [33]. The equations are also summarized in a contribution by Samoc et al. [34]. For linear as well as nonlinear absorption the corresponding absorption cross sections are proportional to the squares of the respective moments. In one-photon absorption processes it is customary to give the dimensionless oscillator strength $(f)$ as the measure of absorption strength and we adopt to this tradition, and for the two-photon absorption process we present cross sections $\left(\sigma^{\mathrm{TP}}\right)$ in units of Göppert-Mayer (GM).

\subsection{Measurements and instrumentation}

IR spectra were recorded for neat compounds using a Mattson ATI 60AR FTIR equipped with a Golden Gate Single Reflection Diamond ATR accessory. ${ }^{1} \mathrm{H}$ and ${ }^{13} \mathrm{C}$ NMR measurements were carried out on a Bruker DRX $400 \mathrm{MHz}$, and chemical shifts are reported relative to TMS as internal reference using $\mathrm{CDCl}_{3}$ as solvent. Mass spectra were obtained from a JMS-SX/SX102A double focusing magnetic sector mass spectrometer (Jeol, Tokyo), using direct inlet and electron impact ionisation (EI+), with ionizing voltage $70 \mathrm{eV}$, acceleration voltage $10 \mathrm{kV}$, and resolution 1000 . Elemental analyses were performed by Mikrokemi AB, Uppsala, Sweden. Optical limiting spectra were recorded with a $\mathrm{f} / 5$ focusing system using a frequency doubled Nd:YAG laser delivering $5 \mathrm{~ns}$ pulses at $532 \mathrm{~nm}$ with a repetition rate of $10 \mathrm{~Hz}[35,36]$. OPL data were obtained for tetrahydrofuran (THF) solutions in $2 \mathrm{~mm}$ quartz cuvets. THF of p.a. quality was used for photophysical measurements. The OPL of neat THF in a quartz cuvet was found to be insignificant compared with that of solutions of the investigated compounds. UV-visible spectra were recorded on a Shimadzu UV-3101PC spectrophotometer in dual mode using $10 \mathrm{~mm}$ quartz cells and THF as solvent and were 


\subsection{Synthesis}

Phenylacetylene, 4-pentylphenylacetylene, 2,5-diiodothiophene, 2,3,5tribromothiophene, triphenylphosphine $\left(\mathrm{PPh}_{3}\right), \mathrm{CuI}$ and $\mathrm{PdCl}_{2}\left(\mathrm{PPh}_{3}\right)_{2}$ were obtained from Aldrich and were used as received. Triethylamine (TEA), pyridine and the solvents used in the reactions were of p.a. quality. TLC was performed on silica gel 60 $\mathrm{F}_{254}$ (Merck) and flash column chromatography was performed on silia gel (Matrex 60 $\AA$, 35-70 $\mu \mathrm{m}$, Grace Amicon). 2,5-Di(4-pentylphenylethynyl)thiophene (S1-Pe), 3dodecyl-2,5-di(4-(4-pentylphenylethynyl)phenylethynyl)thiophene (S2-Pe), and 3dodecyl-2,5-di(4-(4-(4-pentylphenylethynyl)phenylethynyl)phenylethynyl)thiophene (S3-Pe), were prepared as previously reported [21]. The last step in the synthesis of the target compounds was a $\mathrm{Pd}(0)-\mathrm{Cu}(\mathrm{I})$-catalyzed cross-coupling (Scheme) [39]. Even though a comparison with a tellurophene such as Te1 or Te1-Pe was planned, attempts to synthesize tellurophenes indicated that their thermal stability would not be sufficient for OPL experiments, and the work was therefore suspended.

\section{Scheme can be inserted here}

\subsubsection{2,5-Di(4-pentylphenylethynyl)furan (O1-Pe)}

2,5-Dibromofuran [40] (0.43 g, $1.9 \mathrm{mmol})$ was dissolved in a mixture of $20 \mathrm{ml}$ tetrahydrofuran (THF) and $15 \mathrm{ml}$ TEA under argon atmosphere. To the solution was 
added $\mathrm{CuI}(25 \mathrm{mg}, 0.13 \mathrm{mmol}), \mathrm{PdCl}_{2}\left(\mathrm{PPh}_{3}\right)_{2}(60 \mathrm{mg}, 0.085 \mathrm{mmol})$ followed by dropwise addition of the alkyne $(1.0 \mathrm{~g}, 5.8 \mathrm{mmol})$. The color of the solution changed rapidly from orange to pale yellow. The reaction mixture was heated to reflux and stirred for $20 \mathrm{~h}$. The solvent was removed under reduced pressure and the residue was dissolved in $\mathrm{CH}_{2} \mathrm{Cl}_{2}$, washed with $50 \mathrm{ml} 1 \mathrm{M} \mathrm{HCl}$ and water. The organic phase was dried with $\mathrm{MgSO}_{4}$, concentrated and flash chromatographed on silica using heptane as eluent. The product was obtained as white crystals, $0.36 \mathrm{~g}(46 \%)$. IR: $v\left(\mathrm{~cm}^{-1}\right) 2207 ;{ }^{1} \mathrm{H}-$ $\operatorname{NMR}\left(\mathrm{CDCl}_{3}\right): \delta 7.42(\mathrm{~d}, J=8 \mathrm{~Hz}, 4 \mathrm{H}), 7.15(\mathrm{~d}, J=8 \mathrm{~Hz}, 4 \mathrm{H}), 6.61(\mathrm{~s}, 2 \mathrm{H}), 2.59$ (t, $J=$ $8 \mathrm{~Hz}, 4 \mathrm{H}), 1.59(\mathrm{~m}, 4 \mathrm{H}), 1.29(\mathrm{~m}, 8 \mathrm{H}), 0.87$ (t, $J=7 \mathrm{~Hz}, 6 \mathrm{H}) ;{ }^{13} \mathrm{C}-\mathrm{NMR}\left(\mathrm{CDCl}_{3}\right): \delta$ 144.2 ; 137.7, 131.4, 128.5, 119.1, 115.9, 94.3, 78.7, 35.9, 31.4, 30.9, 22.5, 14.0; EI+ MS: m/z (int \%) 84 (100), 408 (55); Anal. Calcd. for $\mathrm{C}_{30} \mathrm{H}_{32} \mathrm{O}$ (\%): C, 88.19; H, 7.89; Found: C, 88.3; H, 8.0.

\subsubsection{2,5-Di(phenylethynyl)thiophene (S1)}

This compound was synthesized similar to a known procedure [41], but using 2,5diiodothiophene, TEA and $\mathrm{PdCl}_{2}\left(\mathrm{PPh}_{3}\right)_{2}$ instead of the reported chemicals. The workup and chromatography were done as described for O1-Pe. The product was obtained in 74 $\%$ yield. The IR and NMR $\left({ }^{1} \mathrm{H},{ }^{13} \mathrm{C}\right)$ data were in accord with those reported in ref. [41].

\subsubsection{2,5-Di-(4-methoxyphenylethynyl)thiophene (S1-OMe)}

The reaction was performed in a Smith Synthesizer single-mode microwave cavity (Personal Chemistry AB, Uppsala, Sweden). To a heavy-walled glass Smith process vial, 2,5-diiodothiophene (0.20 g, $0.60 \mathrm{mmol}), \mathrm{CuI}(40 \mathrm{mg}, 0.21 \mathrm{mmol}), \mathrm{PPh}_{3}(50 \mathrm{mg}$, $0.19 \mathrm{mmol}), \mathrm{PdCl}_{2}\left(\mathrm{PPh}_{3}\right)_{2}$ (92 mg, $\left.0.13 \mathrm{mmol}\right), 1$-ethynyl-4-methoxy-benzene (0.20 g, $1.5 \mathrm{mmol})$, dimethylformamide $(1.5 \mathrm{ml})$ and TEA $(1.5 \mathrm{ml})$ was added. A small magnet was used for stirring and the vial was sealed with an aluminium crimp cap fitted with a silicon septum. The reaction was performed at $120^{\circ} \mathrm{C}$ for $240 \mathrm{~s}$. The workup and chromatography (heptane/ethyl acetate 20:1) were done as described for O1-Pe. A yellow solid (0.17 g, $83 \%$ yield) was obtained. IR: $v\left(\mathrm{~cm}^{-1}\right) 2202 ;{ }^{1} \mathrm{H}$ NMR (400 MHz, $\left.\mathrm{CDCl}_{3}\right): \delta 7.46(\mathrm{~d}, J=9 \mathrm{~Hz}, 4 \mathrm{H}), 7.11(\mathrm{~s}, 2 \mathrm{H}), 6.88(\mathrm{~d}, J=9 \mathrm{~Hz}, 4 \mathrm{H}), 3.83(\mathrm{~s}, 6 \mathrm{H}) ;{ }^{13} \mathrm{C}$ NMR (100 MHz, $\left.\mathrm{CDCl}_{3}\right): \delta 160.02,133.11,131.44,124.7,114.8,114.18,94.06,81.21$, 55.41; Anal. Calcd. for $\mathrm{C}_{22} \mathrm{H}_{16} \mathrm{O}_{2} \mathrm{~S}(\%)$ : C, 76.72; H, 4.68; Found: C, 76.7; H, 4.8. 


\subsubsection{2,3,5-Tri(4-pentylphenylethynyl)thiophene (S1A-Pe)}

2,3,5-Tribromothiophene (1.9 g, $5.9 \mathrm{mmol})$ was dissolved in a deoxygenated mixture of $20 \mathrm{ml}$ dry pyridine and $20 \mathrm{ml}$ dry TEA under argon atmosphere. $\mathrm{PdCl}_{2}\left(\mathrm{PPh}_{3}\right)_{2}(0.10 \mathrm{~g}$, $0.14 \mathrm{mmol})$, and $\mathrm{CuI}(0.1 \mathrm{~g}, 0.05 \mathrm{mmol})$ were added to the solution, followed by dropwise addition of 4-pentyl-1-ethynylbenzene ( $4.0 \mathrm{~g}, 23 \mathrm{mmol})$. The reaction was stirred for 24 hours at room temperature followed by reflux for an additional 48 hours. A dark solution was formed. The workup and chromatography were done as described for O1-Pe. A red oil was obtained, $0.98 \mathrm{~g}(27 \%)$. IR: $v\left(\mathrm{~cm}^{-1}\right) 2195 ;{ }^{1} \mathrm{H}$ NMR $\left(\mathrm{CDCl}_{3}\right)$ : $\delta 7.46(\mathrm{~d}, J=8 \mathrm{~Hz}, 4 \mathrm{H}), 7.40(\mathrm{~d}, J=8 \mathrm{~Hz}, 2 \mathrm{H}), 7.19(\mathrm{~s}, 1 \mathrm{H}), 7.15(\mathrm{~m}, 6 \mathrm{H}), 2.61(\mathrm{t}, J=$ $8 \mathrm{~Hz}, 6 \mathrm{H}), 1.61(\mathrm{~m}, 6 \mathrm{H}), 1.31(\mathrm{~m}, 12 \mathrm{H}), 0.89(\mathrm{t}, J=7 \mathrm{~Hz}, 9 \mathrm{H}) ;{ }^{13} \mathrm{C} \mathrm{NMR}\left(\mathrm{CDCl}_{3}\right): \delta$ 144.1, 144.1, 143.7, 133.3, 131.6, 131.5, 128.5, 128.5, 126.7, 126.5, 123.3, 120.1, $119.8,119.5,98.6,94.6,93.7,82.9,81.4,81.2,35.9,31.4,30.9,30.9,22.5,14.0$; EI+ MS: $\mathrm{m} / \mathrm{z}$ (int \%) $=424$ (100), 594 (0.3). Anal. Calcd. for $\mathrm{C}_{43} \mathrm{H}_{46} \mathrm{~S}(\%)$ : C, 86.82; $\mathrm{H}$, 7.79; Found: C, 86.5; H, 8.1.

\subsubsection{2,5-Di(phenylethynyl)selenophene (Se1)}

2,5-Dibromoselenophene [42] $(0.069 \mathrm{~g}, 0.24 \mathrm{mmol})$ was dissolved in a mixture of THF $(1.5 \mathrm{ml})$ and TEA (1.5 ml) under Ar atmosphere. $\mathrm{PdCl}_{2}\left(\mathrm{PPh}_{3}\right)_{2}(5 \mathrm{mg}, 0.007 \mathrm{mmol}), \mathrm{CuI}$ (2 mg, $0.01 \mathrm{mmol})$ and $\mathrm{PPh}_{3}(2.0 \mathrm{mg}, 0.008 \mathrm{mmol})$ was added to the solution, followed 
by dropwise addition of phenylacetylene $(0.026 \mathrm{~g}, 0.25 \mathrm{mmol})$. The reaction was stirred for $48 \mathrm{~h}$ at room temperature. The workup and chromatography were done as described for 01-Pe. The product was obtained as a yellow white solid, $0.039 \mathrm{~g}$, in $49 \%$ yield; IR: $v\left(\mathrm{~cm}^{-1}\right): 2198 \mathrm{~s} ;{ }^{1} \mathrm{H}-\mathrm{NMR}\left(\mathrm{CDCl}_{3}\right): \delta 7.55-7.49(\mathrm{~m}, 4 \mathrm{H}), 7.38-7.31(\mathrm{~m}, 8 \mathrm{H}) ;{ }^{13} \mathrm{C}-$ NMR $\left(\mathrm{CDCl}_{3}\right): \delta 134.27,131.48,129.44,128.73,128.52,122.89,96.07,84.72$. Anal. Calcd. for C20H12Se (\%): C, 72.51; H, 3.65; Found: C, 72.2; H, 3.8.

\section{Results and discussion}

In order to have ESA to function well for OPL, the absorption coefficient for transition from the electronic ground state $\left(\mathrm{S}_{0}\right)$ to an excited state should be relatively small to provide the high transmittance at normal light intensity, but should be non-zero so that the excited state nevertheless can become populated by high-intensity light. In addition, the absorption from the initial excited state to higher electronic states should be large. Relaxation from the upper excited states should be fast enough to avoid depletion of the levels associated with the important absorption processes. Intersystem crossing from excited singlet to triplet $(\mathrm{T})$ states having strong optical absorption can be advantageous since $\mathrm{T}$ states generally have longer lifetimes than excited singlet states.

To aid in the design of OPL chromophores, one-photon absorption (OPA), ESA and TPA properties were calculated for compounds previously prepared in our laboratory or for model compounds of these, and for a few structurally related compounds not prepared earlier. Several of the synthesized compounds had alkyl substituents to improve solubility. To shorten the time for the quantum chemistry calculations, the alkyl groups were replaced by hydrogens. Two new compounds were subsequently synthesized and their OPL were measured at the wavelength of $532 \mathrm{~nm}$, for the comparison with calculated data. As stated in the Experimental section, geometry optimizations were performed using the B3LYP method with cc-pVDZ and ECP basis sets. For all compounds, the outer rings were found to be coplanar with the central ring, but since the barrier for interring twisting is expected to be low [43], the experimental data will likely represent an average of conformations with varying degree of interring twist. Because of this, we will limit our comparisons to calculated excitation energies and peak maxima in the experimental absorption spectra, and generally not 


\subsection{Calculations of one-photon absorption}

The calculations of electronic absorption spectra were performed using first-principles methods. The core electron densities of S, Se and Te were not included explicitly in the parameterization of the Hartree-Fock and Kohn-Sham determinants, but, instead, relativistic spin-free ECPs were used. This approach does not only reduce the computational effort but also increase the accuracy by providing relativistically correct potentials for the motions of the valence electrons. We have previously made a series of benchmarking calculations that show the virtues and limitations of ECP calculations for linear and nonlinear valence electron properties [34,45-47]. In summary, these investigations showed that excitation energies and one-photon moments can be quite accurately determined with use of ECPs but that two-photon moments in reality break spin selection rules even for light compounds. (The integrated TPA cross sections may, however, be of fair quality with the ECP approach) [46].

The electronic structure of the ground state of all molecules in the present study is closed-shell in nature and the ground state is therefore denoted as $X^{l} A_{l}$ in all cases. The one-photon absorption spectra will be dominated by spin-allowed transitions to states of spatial $B_{2}$ symmetry, i.e., transitions induced by an electric field polarized along the molecular conjugation axis. The lowest transition of this type is well characterized by an electronic transition from the highest-occupied molecular orbital (HOMO) to the lowest-unoccupied molecular orbital (LUMO). Both these MOs are of $\pi$-type and the HOMO (of symmetry $A_{2}$ ) has a node in the $x z$-plane while the LUMO (of symmetry $B_{1}$ ) has a significant electron density at the position of the heavy atom.

An investigation of the sensitivity of the linear absorption spectra with respect to computational parameters was performed for compound $\mathbf{S 1}$ and the results from this 
investigation are compiled in Table 1. From the results presented in the table it can be concluded that the use of ECPs (which in a sense corresponds to a frozen core electron density) does not inflict a loss in accuracy for linear absorption properties; if one compares the two first rows, it is seen that the excitation wavelength $\left(\lambda_{\text {exc }}\right)$ and the oscillator strength is practically unchanged from the all-electron calculation to the corresponding ECP calculation. This justifies the use of the ECPs for the heavy atoms in the remainder of this work. It can also be concluded from the B3LYP and B3LYP-CAM results in Table 1 that the double- $\zeta$ basis set $[\mathrm{cc}-\mathrm{pVDZ}+\mathrm{ECP}(\mathrm{pd})]$ is sufficient in order to describe this valence electron transition (the excitation wavelength differs no more than $4 \mathrm{~nm}$ when compared to the result obtained with the corresponding triple- $\zeta$ basis set). The experimental absorption maximum $\left(\lambda_{\max }\right)$ is found at a wavelength of $348 \mathrm{~nm}$ for S1 in THF, see Table 2. One explanation for the smaller value of $\lambda_{\max }$ compared to the CAM-B3LYP/daug-cc-pVDZ value of $363 \mathrm{~nm}$ can be that conformations with an inter-ring twist, and hence lower conjugation, contribute to the former value. In the present work, we have chosen not to address solvent effects and nuclear vibrations, and will thus accept discrepancies of this size between theoretical and experimental results.

Recent developments of exchange-correlation functionals have shown that such functionals based on the Coulomb attenuated method give an appropriate description of time-dependent response properties. For instance, it has been found that the CAMB3LYP functional performs well for estimations of excitation energies of organic dyes $[48,49]$, and can give results in close agreement with coupled cluster methods for calculations of TPA energies and transition strengths of valence excited states [50]. We therefore consider the CAM-B3LYP results of linear as well as nonlinear response properties to be the most appropriate in this study. Concerning the various choices of basis sets that appear in Table 1, we consider the best to be the cc-pVDZ basis set augmented with two sets of diffuse functions (daug-cc-pVDZ). However, from the results in the table it is clear that single augmentation is adequate in the present case, and in the discussion below the CAM-B3LYP/aug-cc-pVDZ results are considered to be the theoretical reference data.

\section{Table 1 can be inserted here}

The linear absorption of several other chalcogenophenes was calculated and the results are presented in Table 2. Notice that many of the molecular structures for 
calculations were simplified in order to reduce the computational efforts, but that the calculated and experimental data are comparable for structures which differ only by the length of the alkyl chain or where the alkyl chain is 'replaced' with a hydrogen, since such modifications should have only small effects on the $\pi$-system of the compound. A comparison between the calculated data shows the same trends as discussed above with respect to method and basis set. It is also found that although the choice of method and to some degree basis set has an effect on the absolute values of excitation wavelengths and oscillator strengths, the relative order amongst the molecules remains the same. The dominating linear absorption for the compounds with short conjugation length is generally found in the ultraviolet region just outside the visible range, and the compounds were thus expected to be only slightly coloured. A red-shift in the absorption occurs when: (a) the number of repeat units in the ligands is increased, which results in an increased charge-conjugation length and a smaller bandgap, or (b) the heteroatom in the ring is replaced by a heavier atom, which can be explained by the smaller energy gap between occupied and virtual orbitals in heavy atoms. The comparison of the experimental values for S1 and S1-Pe shows that the substitution of the peripheral alkyl group for hydrogen only slightly changes the value of $\lambda_{\max }$. With the reasonable assumption that this is valid also for comparisons of O1-Me and O1-Pe with the alkyl- or unsubstituted S, Se and Te compounds, it is noticed that the CAM-B3LYP calculated redshift of $13 \mathrm{~nm}$ from $\mathbf{0 1 - M e}$ to $\mathbf{S 1}$ is in good agreement with the $\lambda_{\max }$ redshifts from O1-Pe to S1 and O1-Pe to S1-Pe of $10 \mathrm{~nm}$ and $14 \mathrm{~nm}$, respectively. The absorption redshift as due to a substitution of selenium for sulfur (Se1 compared to S1) is $14 \mathrm{~nm}$ at the CAM-B3LYP level of theory and $11 \mathrm{~nm}$ in the experiment. The redshift as due to a substitution of tellurium for selenium (Te1 compared to Se1) is predicted to be $13 \mathrm{~nm}$ at the same level of theory. We have not been able to synthesize the tellurophene compounds and can therefore not make a comparison with experiment in this case.

The presence of the $\mathrm{OCH}_{3}$ termination group instead of $\mathrm{H}$ for the $\mathrm{S}$, Se and Te compounds does not affect the theoretical band-gap energies significantly. On the other hand, the dipole moments are largely affected and this could be expected to have an effect on the solvent organization in ground and excited states. However, the difference in $\lambda_{\max }$ between $\mathbf{S 1}$ and S1-OMe $(8 \mathrm{~nm})$ is virtually the same as the CAM-B3LYP value $(6 \mathrm{~nm})$. Further, we found that $\lambda_{\max }$ of S1-OMe differs very little between THF (356 
$\mathrm{nm})$ and toluene $(358 \mathrm{~nm})$ solution, which suggests that THF can be regarded as a nonpolar solvent in the context of excitations in the compounds of this study.

For S1-NO2a as compared to S1, a red-shift of $27 \mathrm{~nm}$ is predicted at the CAMB3LYP level. Because such a shift will result in more coloured samples, the alternative structure S1-NO2b, with the nitro groups in positions 3 and 4 in the ring, was also examined theoretically. In this configuration, with adjacent $\mathrm{NO}_{2}$ groups, the $\mathrm{N}$ and $\mathrm{O}$ atoms cannot be coplanar with the ring atoms due to steric reasons [51]. A twist of the $\mathrm{NO}_{2}$ groups relative to the ring plane was also found by the calculations. The calculated excitation wavelength of S1-NO2b is quite similar to that of S1. Because of this expected favourable transmittance, S1-NO2-Pe instead of S1-NO2a was synthesized and characterized. It is clear from the results in Table 2, however, that the experimental redshift associated with the substitution of nitro groups for hydrogens amounts to $38 \mathrm{~nm}$ ( $\lambda_{\max }$ of S1-Pe and S1-NO2-Pe), as compared to the blueshift of $2 \mathrm{~nm}$ in theory. Such a large quantitative and also qualitative discrepancy in results may be due to solvation effects associated with the large changes in dipole moment on excitation.

\section{Table 2 can be inserted here}

In concern with the theoretical calculations of the linear absorption spectra of the chalcogenophenes we conclude that the Coulomb attenuated functional is needed for an appropriate description of the dominating electronic transitions of the compounds. With use of the CAM-B3LYP functional, we obtain a realistic description of the unsubstituted, alkyl- and methoxy-substituted chalcogenophene compounds, where calculated transition wavelengths and heavy-atom induced redshifts agree well with experiment. However, for compounds with nitro groups, we suspect that solvation effects associated with large dipole moment changes can influence the data, which we have not accounted for.

In the presentation below of excited state and nonlinear absorption properties, we will restrict ourselves to only provide results obtained with the CAM-B3LYP functional.

\subsection{Calculations of excited state absorption}

The dominating state in the linear absorption spectrum is $1^{1} B_{2}$ in all systems included in the present study, and we have therefore focused calculations of excited state absorption 
to a situation where this state is the initial state in the absorption process. The final state is of singlet spin symmetry and, due to the predominance for absorption of light polarized along the conjugation axis, the spatial symmetry will be $A_{1}$. ESA calculations were performed on unsubstituted, methoxy- and nitro-substituted compounds, see Table 3. As a general trend, the CAM-B3LYP results suggest strong ESA in the red end of the visible region for all compounds. It is also noted that the wavelength of the transition with largest oscillation strength is shifted towards lower values in the order O1-Me, S1, Se1, Te1 $(807,788,748$ and $735 \mathrm{~nm}$, respectively). The same trend is found for the three methoxy-substituted compounds (806, 737 and $725 \mathrm{~nm}$, respectively). We note that the ESA of $\mathbf{S 1}$ has also been determined using the double augmented basis set (see footnote "a" of Table 3 ) and that the results for the dominant transitions are in close agreement with the results obtained using the single augmented basis set. However, an electronic transition appears at $415 \mathrm{~nm}$ at the CAM-B3LYP/daug-cc-pVDZ level with an oscillator strength of 0.093 , which may contribute to the OPL in the blue region. The theoretical results indicate that there is much to gain in the OPL performance in the blue and green regions of the spectrum by enhancing the singlet state ESA in those regions. The blueshifts associated with the heavy-atom substitutions are not sufficient in this respect.

\section{Table 3 can be inserted here}

\subsection{Calculations of two-photon absorption}

In the present systems, the absorption of two photons in a simultaneous coherent process is only effective if both light quanta are polarized along the conjugation axis and the final state in the process is therefore of $A_{1}$ symmetry. The dominating states in the TPA spectra of the studied molecules are those that we have discussed in concern with excited state absorption. In Figure 2, we have plotted the TPA cross section values above $1 \mathrm{GM}$ for the wavelength region of $400-650 \mathrm{~nm}$, as obtained at the CAMB3LYP/aug-cc-pVDZ level of theory. A TPA calculation was also performed with the daug-cc-pVDZ basis set for S1. This comparison between the single and double augmented basis sets show virtually unchanged absorption characteristics, with the two dominant TPA wavelengths above $400 \mathrm{~nm}$ found at $480 \mathrm{~nm}\left(\sigma^{\mathrm{TP}}=124 \mathrm{GM}\right)$ and 497 $\mathrm{nm}\left(\sigma^{\mathrm{TP}}=193 \mathrm{GM}\right)$ for both calculations. 
The most striking observation to be made is that the TPA cross section does not strongly depend on heavy atom substitution. Compounds O1-Me, S1, Se1 and Te1 all have their largest absorption peak in the range of 487-508 $\mathrm{nm}$, although additional somewhat weaker absorptions are found for O1-Me and S1 at 413 and $480 \mathrm{~nm}$, respectively. For S1, it is relevant to sum the intensities of the peaks at 480 and $495 \mathrm{~nm}$; the total TPA cross section for these two states becomes about $330 \mathrm{GM}$ which is close to the cross sections of Se1 (350 GM) and Te1 (360 GM). Hence, from a two-photon efficiency point of view the materials are quite identical but the absorption in S1 is predicted to be somewhat broader than that of the other two due to the split of the intensity over two near-lying electronic states. In resemblance with these four compounds, the three methoxy-substituted compounds and S1-NO2b have their strongest TP absorptions close to $500 \mathrm{~nm}$. All four of the latter compounds have additional noteworthy absorptions in the region of approximately $470-550 \mathrm{~nm}$, but on the whole, the eight investigated compounds have rather similar TPA characteristics. (Although Se1-OMe has a strong TPA peak at $403 \mathrm{~nm}$, this is not likely to be important since one-photon absorption can be expected to dominate at that wavelength).

With respect to the OPL characteristics of these compounds, the TPA bands around $500 \mathrm{~nm}$ are likely to contribute to absorption of $532 \mathrm{~nm}$ laser light due to the effects of vibrational broadening. The extent of its contribution (in comparison to ESA) is very difficult to predict without performing simulations of laser pulse propagation with account made for pulse shape, intensity, duration, etc. Such simulations are beyond the scope of the present work but have been initiated in our group on platinum-based compounds with focus on the contribution from the long-lived excited triplet states $[52,53]$.

\section{Figure 2 can be inserted here}

\subsection{UV-Visible absorption, OPL and steady state and time-resolved luminescence}

The absorption spectra of the compounds in the wavelength range of 250-500 nm are dominated by one strong transition, with a vibrational substructure indicated (Figure 3). Certain compounds, such as S2-Pe, S3-Pe and notably S1-NO2-Pe and S1A-Pe appear to have at least two partially overlapping absorption bands, corresponding to 
Figure 3 can be inserted here

different electronic states. The spectra of S1 (not shown), S1-Pe, S2-Pe, S3-Pe, S1OMe and Se1 have very similar band shape (of the low-energy band) although the longer compounds have their bands red-shifted. The multi-component spectra of S1APe and S1-NO2-Pe differ significantly from those of the other compounds by having a very broad and featureless band shape.

Optical limiting data are summarized in Table 4, as transmitted energy for each compound at a laser input energy of $150 \mu \mathrm{J}$ at $532 \mathrm{~nm}$, for $5 \mathrm{~ns}$ pulses. It should be stressed that this comparison of compounds at a single wavelength is relevant for only a rather narrow wavelength region close to $532 \mathrm{~nm}$. Some trends that can be found in the OPL results are: (a) the change of heteroatom in the ring from $\mathrm{O}$ to $\mathrm{S}$ results in a slightly inferior OPL result, but the change from $S$ to Se improves the OPL capacity to the same level as for the corresponding furane; (b) the lengthening of the $\pi$-system provides better OPL in the order S1-Pe $<$ S2-Pe $<$ S3-Pe; [21] (c) with regard to the substitution pattern, the third phenylethynyl group in S1A-Pe, the methoxy groups in S1-OMe, and in particular the nitro groups in S1-NO2-Pe, result in better OPL for these compounds compared to that of S1-Pe.

\section{Table 4 can be inserted here}

In resemblance with absorption spectra, fluorescence of the compounds revealed peaks with vibrational substructure, however better resolved (Figure 4). The fluorescence quantum yields $\left(Q_{\mathrm{fl}}\right)$ and the lifetimes $\left(\tau_{\mathrm{fl}}\right)$ increase in the order S1-Pe $<$ S2-Pe $<$ S3-Pe as do the OPL capacity at $532 \mathrm{~nm}$, which might be expected if ESA contributes to the OPL process. The values of $Q_{\mathrm{fl}}$ and $\tau_{\mathrm{fl}}$ are almost the same for S1OMe and S1-Pe, and the somewhat lower OPL value of the former may well be explained by more efficient TPA due to the laser wavelength being slightly more appropriate for TPA in S1-OMe, see Figure 2. Both S1-NO2-Pe and Se1 have very small values of $Q_{\mathrm{fl}}$ and $\tau_{\mathrm{fl}}$, and the better OPL of these compounds (particularly of the former) in comparison with S1-Pe is not easily explained by ESA from the $1^{1} B_{2}$ state or 
by TPA according to the results from the calculations. This shows that additional processes need to be considered. In the case of Se1, fast intersystem crossing from an excited singlet to the triplet state manifold due to the heavy-atom effect, with subsequent triplet state absorption, may contribute to the nonlinear absorption. Studies of organoselenium compounds have shown that intersystem crossing can compete with singlet internal conversion, although the latter process may be more efficient [54], and that degassed samples of Se tetramethylrosamine dyes can have a triplet quantum yield close to unity [55].

In the case of S1-NO2-Pe, the linear absorption band has a tail that extends into the green region $(532 \mathrm{~nm})$, which probably results in greater initial population of excited singlet states in comparison with other compounds in this study. As for Se1, the nonlinear absorption of S1-NO2-Pe may to some extent be explained by triplet formation and absorption within the triplet manifold. It is well known that aromatic nitro compounds, including 3,4-dinitrotoluene which has the nitro groups on adjacent carbons [56], can have fast singlet-to-triplet formation and high triplet quantum yields [56-58].

\section{Figure 4 can be inserted here}

The magnitude of the Stokes shifts, estimated from the lowest-energy peaks in the absorption and emission spectra, do not imply changes in the molecular conformations or solvent reorganization, with the exception of S1-NO2-Pe in chloroform (Table 4). In this compound, the HOMO-LUMO type of transition is associated with electron redistribution from the phenyl rings to the $\mathrm{S}$ atom and the $\mathrm{NO}_{2}$ groups at the central ring, as found by the MO calculations. The Stokes shift can therefore, at least partly, be explained by a solvent redistribution after excitation. A twist of the nitro groups to increase conjugation in the excited state may also explain the Stokes shift. However, further studies are required to resolve this and the question regarding changes in molecular geometry in the excited state, as well as the dynamics and absorptions of S1NO2-Pe in the excited state. 
4. Summary

Time-dependent Hartree-Fock and DFT calculations of one-photon absorptions showed a good prediction of experimental wavelengths and oscillator strengths for the investigated chalcogenophenes. Calculations of two-photon absorptions indicated that several of the compounds should have a two-photon cross section of the same order of magnitude in a wavelength range of approximately 490-510 $\mathrm{nm}$. At the wavelength for OPL measurements of the chalcogenophenes $(532 \mathrm{~nm})$ the TPA process can be expected to contribute significantly less to optical power limiting of these compounds. Absorption of the $1^{1} B_{2}$ (excited singlet) state was calculated for several compounds at the CAM-B3LYP/aug-cc-pVDZ level, and the results showed significant ESA at the red end of the visible region, but virtually no absorption close to $532 \mathrm{~nm}$.

The thiophene with nitro groups on the ring carbons (S1-NO2-Pe) showed the strongest OPL of the investigated compounds. The reason for this is not revealed by the calculations or the absorption/emission experiments, but greater initial population of the lowest excited state, in comparison with the other compounds, due to tailing of its absorption band into the green region $(532 \mathrm{~nm}$ ) may be part of the explanation.

\section{Acknowledgements}

This work was supported (BE, CL, ML, PN) by a Swedish Defence Nanotechnology Programme run jointly by the Swedish Defence Research Agency (FOI) and Defence Material Administration (FMV). ML acknowledges a grant from The Research Council of Norway within the NanoMat program, contract \#163529. 


\section{References}

[1] P.N. Prasad, B.A. Reinhardt, Chem. Mater. 2, 660 (1990).

[2] J.L. Bredas, C. Adant, P. Tackx, A. Persoons, and B.M. Pierce, Chem. Rev. 94, 243 (1994).

[3] G.I. Stegeman, Nonlinear Opt. Org. Mol. Polym., edited by H.S. Nalwa, S. Miyata (CRC Press, Boca Raton, 1997), p. 799.

[4] R.C. Hollins, Curr. Opi. Solid State Mat. Sci. 4, 189 (1999).

[5] T. Kaino, J. Opt. A, Pure Appl. Opt. 2, R1 (2000).

[6] G.J. Zhou, W.Y. Wong, C. Ye, and Z.Y. Lin, Adv. Funct. Mater. 17, 963 (2007).

[7] G.S. He, L.-S. Tan, Q. Zheng, and P.N. Prasad, Chem. Rev. 108, 1245 (2008).

[8] G. Ramos-Ortiz, M. Cha, S. Thayumanavan, J. Mendez, S.R. Marder, and B. Kippelen, Appl. Phys. Lett. 85, 3348 (2004).

[9] K.S. Lee, D.Y. Yang, S.H. Park, and R.H. Kim, Polym. Adv. Technol. 17, 72 (2006).

[10] J.W. Perry, Nonlinear Opt. Org. Mol. Polym., edited by H.S. Nalwa, S. Miyata (CRC Press, Boca Raton, 1997), p. 813.

[11] C.W. Spangler, J. Mater. Chem. 9, 2013 (1999).

[12] D. Dini, M. Barthel, and M. Hanack, Eur. J. Org. Chem., 3759 (2001).

[13] J.E. Ehrlich, X.L. Wu, I.Y.S. Lee, Z.Y. Hu, H. Rockel, S.R. Marder, and J.W. Perry, Opt. Lett. 22, 1843 (1997).

[14] B.A. Reinhardt, L.L. Brott, S.J. Clarson, A.G. Dillard, J.C. Bhatt, R. Kannan, L.X. Yuan, G.S. He, and P.N. Prasad, Chem. Mater. 10, 1863 (1998).

[15] J.E. Rogers, B.C. Hall, D.C. Hufnagle, J.E. Slagle, A.P. Ault, D.G. McLean, P.A. Fleitz, and T.M. Cooper, J. Chem. Phys. 122, 214708 (2005).

[16] H.S. Nalwa, Nonlinear Opt. Org. Mol. Polym., edited by H.S. Nalwa, S. Miyata (CRC Press, Boca Raton, 1997), p. 611.

[17] E. Badaeva, S. Tretiak, Chem. Phys. Lett. 450, 322 (2008).

[18] X.J. Xing, J. Li, Y.P. Sun, and C.K. Wang, Theochem-J. Mol. Struct. 849, 116 (2008).

[19] K. Ogawa, Y. Kobuke, J. Photochem. Photobiol., C 7, 1 (2006).

[20] P. Lind, C. Lopes, K. Öberg, and B. Eliasson, Chem. Phys. Lett. 387, 238 (2004).

[21] P. Lind, A. Eriksson, C. Lopes, and B. Eliasson, J. Phys. Org. Chem. 18, 426 (2005).

[22] R. Vestberg, C. Nilsson, C. Lopes, P. Lind, B. Eliasson, and E. Malmström, J. Polym. Sci., Part A: Polym. Chem. 43, 1177 (2005).

[23] J. Staromlynska, T.J. McKay, and P. Wilson, J. Appl. Phys. 88, 1726 (2000).

[24] R. Vestberg, R. Westlund, A. Eriksson, C. Lopes, M. Carlsson, B. Eliasson, E. Glimsdal, M. Lindgren, and E. Malmström, Macromolecules 39, 2238 (2006).

[25] Gaussian-03 Revision C.02, Frisch, M. J.; Trucks, G. W.; Schlegel, H. B.; Scuseria, G. E.; Robb, M. A.; Cheeseman, J. R.; Montgomery, Jr., J. A.; Vreven, T.; Kudin, K. N.; Burant, J. C.; Millam, J. M.; Iyengar, S. S.; Tomasi, J.; Barone, V.; Mennucci, B.; Cossi, M.; Scalmani, G.; Rega, N.; Petersson, G. A.; Nakatsuji, H.; Hada, M.; Ehara, M.; Toyota, K.; Fukuda, R.; Hasegawa, J.; Ishida, M.; Nakajima, T.; Honda, Y.; Kitao, O.; Nakai, H.; Klene, M.; Li, X.; Knox, J. E.; Hratchian, H. P.; Cross, J. B.; Bakken, V.; Adamo, C.; Jaramillo, J.; Gomperts, R.; Stratmann, R. E.; Yazyev, O.; Austin, A. J.; Cammi, R.; Pomelli, 
C.; Ochterski, J. W.; Ayala, P. Y.; Morokuma, K.; Voth, G. A.; Salvador, P.; Dannenberg, J. J.; Zakrzewski, V. G.; Dapprich, S.; Daniels, A. D.; Strain, M. C.; Farkas, O.; Malick, D. K.; Rabuck, A. D.; Raghavachari, K.; Foresman, J. B.; Ortiz, J. V.; Cui, Q.; Baboul, A. G.; Clifford, S.; Cioslowski, J.; Stefanov, B. B.; Liu, G.; Liashenko, A.; Piskorz, P.; Komaromi, I.; Martin, R. L.; Fox, D. J.; Keith, T.; Al-Laham, M. A.; Peng, C. Y.; Nanayakkara, A.; Challacombe, M.; Gill, P. M. W.; Johnson, B.; Chen, W.; Wong, M. W.; Gonzalez, C.; and Pople, J. A.; . Gaussian, Inc., Wallingford CT, 2004.

[28] A. Bergner, M. Dolg, W. Kuchle, H. Stoll, and H. Preuss, Mol. Phys. 80, 1431 (1993).

[29] DALTON, a molecular electronic structure program, Release 2.0 (2005), see http://www.kjemi.uio.no/software/dalton/dalton.html.

[30] T. Yanai, D.P. Tew, and N.C. Handy, Chem. Phys. Lett. 393, 51 (2004).

[31] M.J.G. Peach, T. Helgaker, P. Salek, T.W. Keal, O.B. Lutnaes, D.J. Tozer, and N.C. Handy, Phys. Chem. Chem. Phys. 8, 558 (2006).

[32] W.J. Hehre, R. Ditchfield, and J.A. Pople, J. Chem. Phys. 56, 2257 (1972).

[33] P. Norman, K. Ruud, Nonlinear optical properties of matter: From molecules to condensed phases, edited by M. Papadopoulos, J. Leszczynski, A.J. Sadlej (Kluwer Academic Press, 2006.

[34] M. Samoc, G.T. Dalton, J.A. Gladysz, Q. Zheng, Y. Velkov, H. Agren, P. Norman, and M.G. Humphrey, Inorg. Chem. 47, 9946 (2008).

[35] D. Vincent, J. Cruickshank, Appl. Opt. 36, 7794 (1997).

[36] D. Vincent, MCLC S\&T, Section B: Nonlinear Optics 21, 413 (1999).

[37] J.N. Demas, G.A. Crosby, J. Phys. Chem. 75, 991 (1971).

[38] Jobin, Yvon, and Inc., "A Guide to Recording Fluorescence Quantum Yields", http://www.jobinyvon.com/usadivisions/fluorescence/applications/quantumyield strad.pdf.

[39] K. Sonogashira, Y. Tohda, and N. Hagihara, Tetrahedron Lett., 4467 (1975).

[40] M.A. Keegstra, A.J.A. Klomp, and L. Brandsma, Synth. Commun. 20, 3371 (1990).

[41] T.S. Jung, J.H. Kim, E.K. Jang, D.H. Kim, Y.-B. Shim, B. Park, and S.C. Shin, J. Organomet. Chem. 599, 232 (2000).

[42] S. Gronowitz, T. Frejd, Acta Chem. Scand., Ser. B B30, 313 (1976).

[43] S.J. Greaves, E.L. Flynn, E.L. Futcher, E. Wrede, D.P. Lydon, P.J. Low, S.R. Rutter, and A. Beeby, J. Phys. Chem. A 110, 2114 (2006).

[44] J.S. Siddle, R.M. Ward, J.C. Collings, S.R. Rutter, L. Porres, L. Applegarth, A. Beeby, A.S. Batsanov, A.L. Thompson, J.A.K. Howard, A. Boucekkine, K. Costuas, J.F. Halet, and T.B. Marder, New J. Chem. 31, 841 (2007).

[45] P. Norman, P. Cronstrand, and J. Ericsson, Chem. Phys. 285, 207 (2002).

[46] J. Henriksson, P. Norman, and H.J.A. Jensen, J. Chem. Phys. 122, 114106 (2005).

[47] J. Henriksson, U. Ekstrom, and P. Norman, J. Chem. Phys. 124, 214311 (2006).

[48] D. Jacquemin, E.A. Perpete, G.E. Scuseria, I. Ciofini, and C. Adamo, J. Chem. Theory Comput. 4, 123 (2008).

[49] M.J.G. Peach, P. Benfield, T. Helgaker, and D.J. Tozer, J. Chem. Phys. 128, 044118 (2008).

[50] M.J. Paterson, O. Christiansen, F. Pawlowski, P. Jorgensen, C. Hattig, T. Helgaker, and P. Salek, J. Chem. Phys. 124, 054322 (2006). 
[51] T. Yasuda, T. Imase, Y. Nakamura, and T. Yamamoto, Macromolecules 38, 4687 (2005).

[52] A. Baev, P. Norman, J. Henriksson, and H. Agren, J. Phys. Chem. B 110, 20912 (2006).

[53] A. Baev, P. Welinder, R. Erlandsson, J. Henriksson, P. Norman, and H. Agren, Journal of Nonlinear Optical Physics \& Materials 16, 157 (2007).

[54] S. Dobrin, P. Kaszynski, and J. Waluk, J. Photochem. Photobiol., A 105, 149 (1997).

[55] T.Y. Ohulchanskyy, D.J. Donnelly, M.R. Detty, and P.N. Prasad, J. Phys. Chem. B 108, 8668 (2004).

[56] S.K. Chattopadhyay, B.B. Craig, J. Phys. Chem. 91, 323 (1987).

[57] R. Hurley, A.C. Testa, J. Am. Chem. Soc. 90, 1949 (1968).

[58] J. Lorenc, E. Kucharska, J. Hanuza, and H. Chojnacki, J. Mol. Struct. 707, 47 (2004). 
Figure captions:

Scheme. Pd-Cu-catalyzed cross-coupling in the synthesis of arylalkynylchalcogenophenes.

Figure 1. Compounds in the studied chalcogenophene series.

Figure 2. Theoretical two-photon absorption cross sections $\left(\sigma^{\mathrm{TP}}\right)$ for photon wavelengths in the visible region for eight chalcogenophenes (upper and lower panels). Results are obtained at the CAM-B3LYP/aug-cc-pVDZ level of theory.

Figure 3. Absorption spectra of chalcogenophenes S1-Pe, S2-Pe, S3-Pe and Se1 (upper panel) and O1-Pe, S1-OMe, S1-NO2-Pe and S1A-Pe (lower panel), in THF.

Figure 4. Fluorescence emission from eight chalcogenophenes (upper and lower panels); ca. $2 \cdot 10^{-5} \mathrm{M}$ in THF and $337 \mathrm{~nm}$ excitation wavelength. The emission traces of Se1 and S1-NO2-Pe are enhanced by a factor of 10 for clarity. 
Scheme:

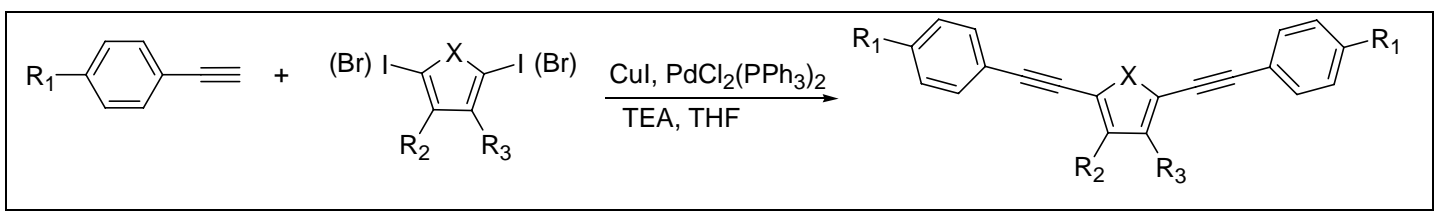




\begin{tabular}{cccccc}
\hline Compound acronym & $\mathrm{X}$ & $\mathrm{n}$ & $\mathrm{R}_{1}$ & $\mathrm{R}_{2}$ & $\mathrm{R}_{3}$ \\
\hline O1-Me & $\mathrm{O}$ & 1 & $\mathrm{CH}_{3}$ & $\mathrm{H}$ & $\mathrm{H}$ \\
S1, Se1, Te1 & $\mathrm{S}, \mathrm{Se}, \mathrm{Te}$ & 1 & $\mathrm{H}$ & $\mathrm{H}$ & $\mathrm{H}$ \\
S2, Se2, Te2 & $\mathrm{S}, \mathrm{Se}, \mathrm{Te}$ & 2 & $\mathrm{H}$ & $\mathrm{H}$ & $\mathrm{H}$ \\
S3, Se3, Te3 & $\mathrm{S}, \mathrm{Se}, \mathrm{Te}$ & 3 & $\mathrm{H}$ & $\mathrm{H}$ & $\mathrm{H}$ \\
O1-Pe, S1-Pe & $\mathrm{O}, \mathrm{S}$ & 1 & $n-\mathrm{C}_{5} \mathrm{H}_{11}$ & $\mathrm{H}$ & $\mathrm{H}$ \\
S2-Pe, S3-Pe & $\mathrm{S}$ & 2,3 & $n-\mathrm{C}_{5} \mathrm{H}_{11}$ & $n-\mathrm{C}_{12} \mathrm{H}_{25}$ & $\mathrm{H}$ \\
S1-OMe, Se1-OMe, Te1-OMe & $\mathrm{S}, \mathrm{Se}, \mathrm{Te}$ & 1 & $\mathrm{OCH}_{3}$ & $\mathrm{H}$ & $\mathrm{H}$ \\
S1-NO2a, Se1- NO2a, Te1- NO2a & $\mathrm{S}, \mathrm{Se}, \mathrm{Te}$ & 1 & $\mathrm{NO}_{2}$ & $\mathrm{H}$ & $\mathrm{H}$ \\
S1-NO2b & $\mathrm{S}$ & 1 & $\mathrm{H}_{2}$ & $\mathrm{NO}_{2}$ & $\mathrm{NO}_{2}$ \\
S1-NO2-Pe & $\mathrm{S}$ & 1 & $n-\mathrm{C}_{5} \mathrm{H}_{11}$ & $\mathrm{NO}_{2}$ & $\mathrm{NO}_{2}$ \\
S1A-Pe & $\mathrm{S}$ & 1 & $n-\mathrm{C}_{5} \mathrm{H}_{11}$ & $\mathrm{CC}-p-\mathrm{C}_{6} \mathrm{H}_{4}-n-\mathrm{C}_{5} \mathrm{H}_{11}$ & $\mathrm{H}$
\end{tabular}

Figure 1. 

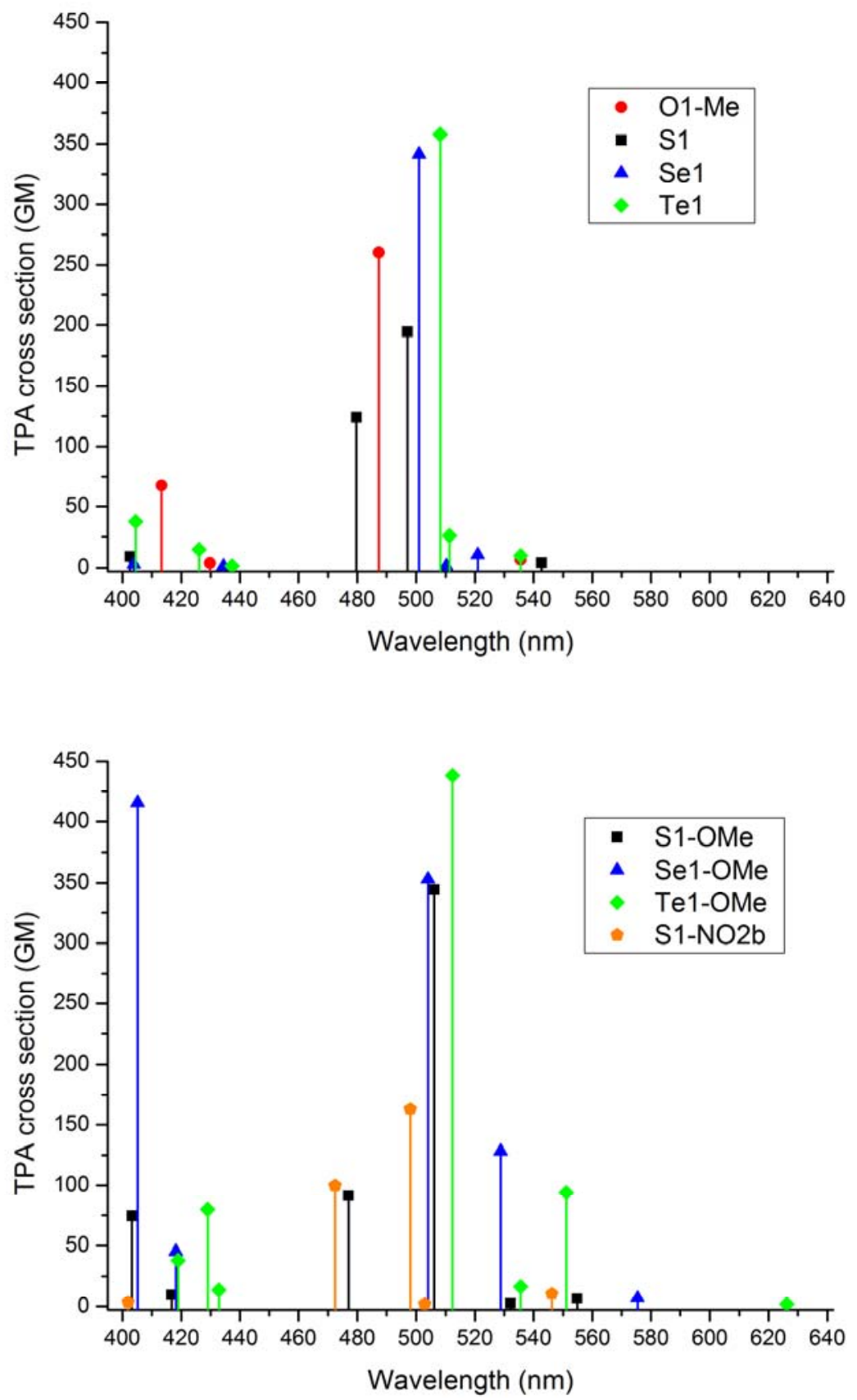

Figure 2.

URL: http://mc.manuscriptcentral.com/tandf/tmph 


1
1
3
4
5
6
7
8
9
10
11
12
13
14
15
16
17
18
19
20
21
22
23
24
25
26
27
28
29
30
31
32
33
34
35
36
37
38
39
40
41
42
43
44
55
50
56
57
48
59
50
51
53
50
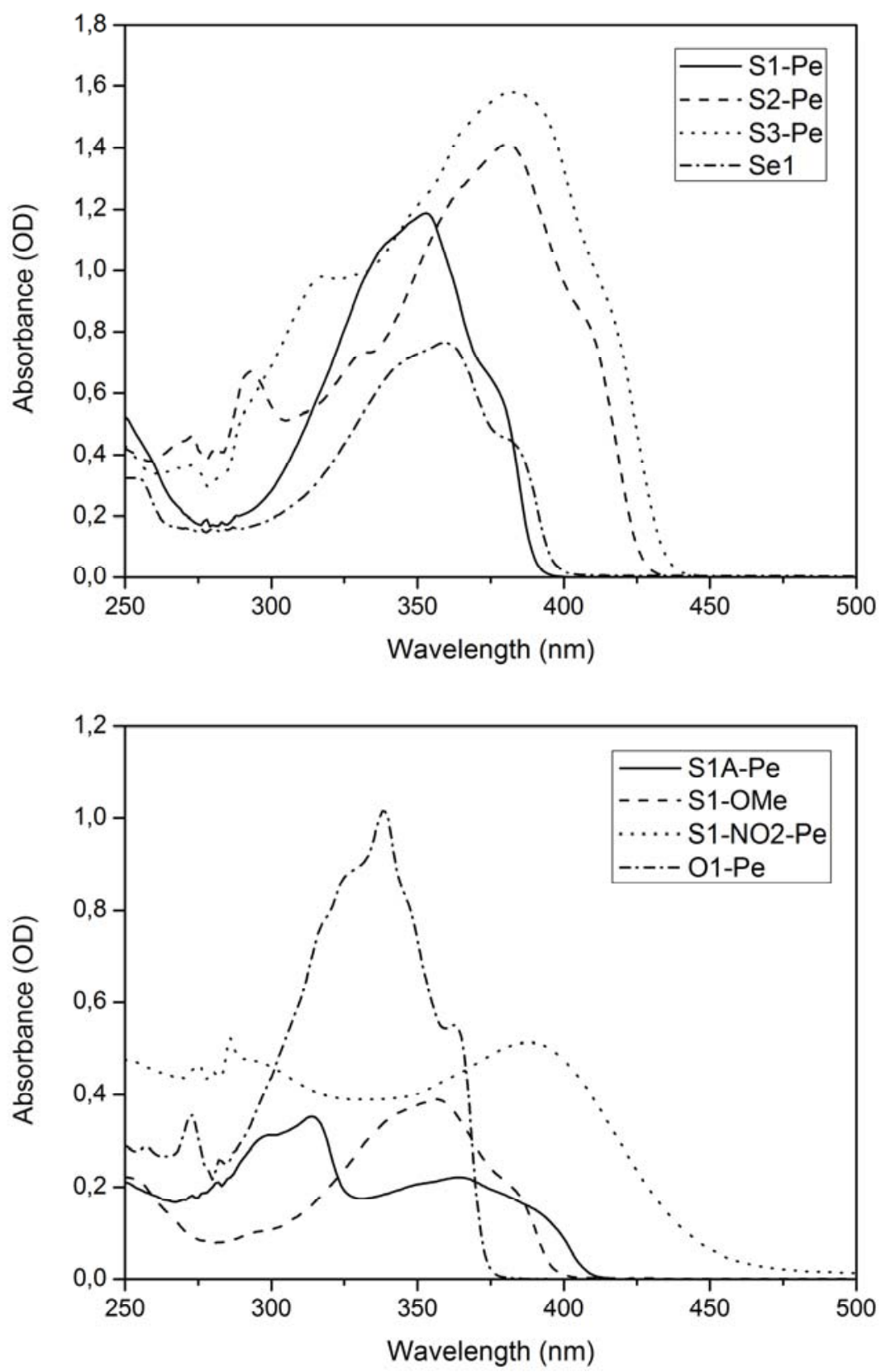

Figure 3. 

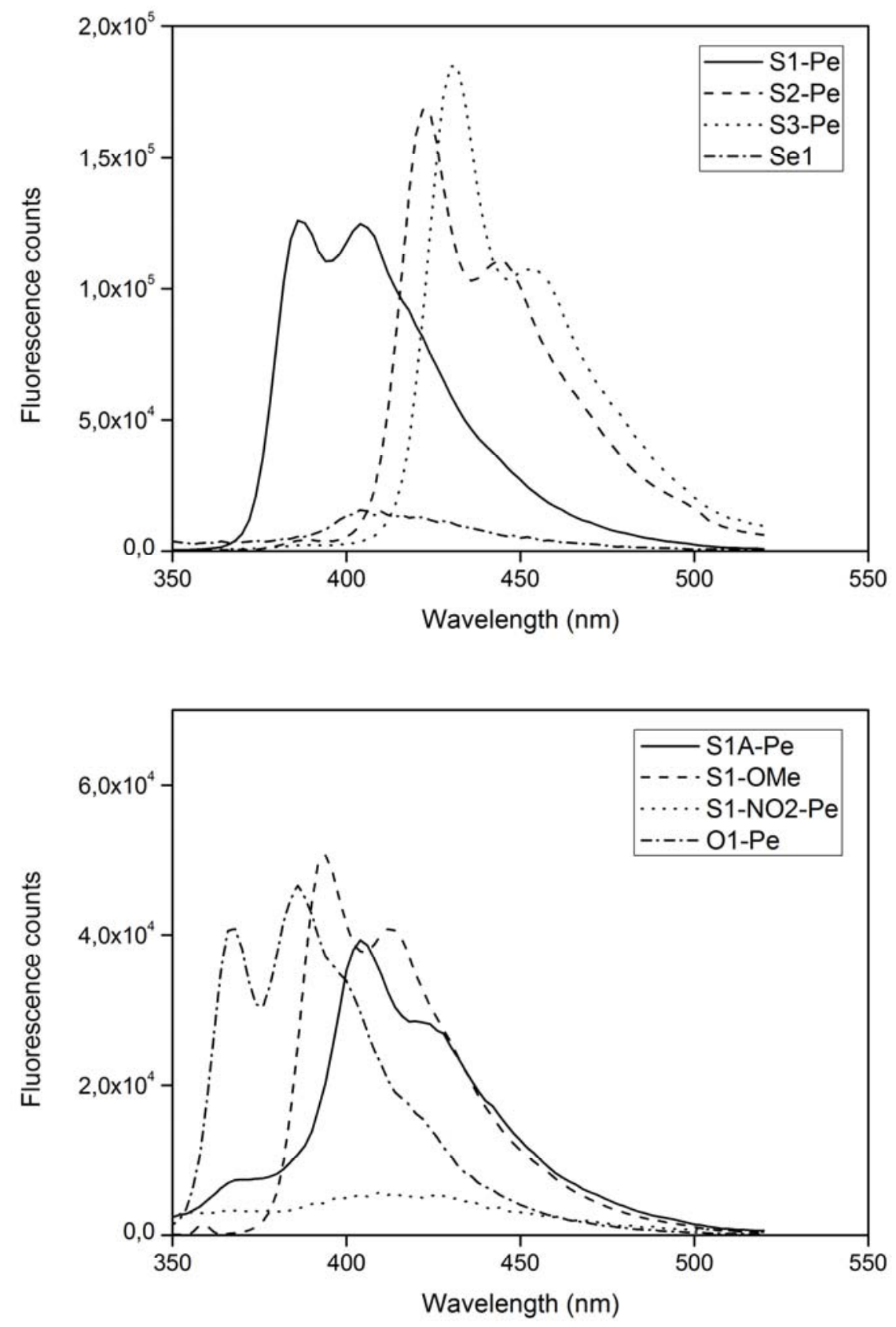

Figure 4.

URL: http://mc.manuscriptcentral.com/tandf/tmph 
Table 1. Calculated excitation wavelength ( $\lambda_{\text {exc }}$ ) and oscillator strength ( $f$ ) for the $X^{1} A_{1} \rightarrow 1^{1} B_{2}$ transition for compound S1.

\begin{tabular}{|c|c|c|c|c|c|c|}
\hline \multirow{2}{*}{ Basis set ${ }^{a}$} & \multicolumn{3}{|c|}{$\lambda_{\text {exc }}(\mathrm{nm})$} & \multicolumn{3}{|c|}{$f$} \\
\hline & $\mathrm{HF}$ & B3LYP & CAM-B3LYP & $\mathrm{HF}$ & B3LYP & CAM-B3LYP \\
\hline $6-31 G$ & 327 & 382 & 345 & 1.35 & 1.57 & 1.56 \\
\hline 6-31G, ECP & 326 & 381 & 345 & 1.35 & 1.59 & 1.53 \\
\hline 6-31++G, ECP(pd) & 332 & 388 & 349 & 1.32 & 1.55 & 1.56 \\
\hline cc-pVDZ, ECP(pd) & & 395 & 358 & & 1.56 & 1.53 \\
\hline cc-pVTZ, ECP(pd) & 344 & 398 & 362 & 1.37 & 1.56 & 1.53 \\
\hline aug-cc-pVDZ, ECP(pd) & & & 362 & & & 1.53 \\
\hline daug-cc-pVDZ, ECP(pd) & & & 363 & & & 1.52 \\
\hline
\end{tabular}

Note: ${ }^{a}$ The parenthesis denotes the presence of polarization (p) and diffuse (d) functions in the ECP. 
Table 2. HF and DFT calculated excitation wavelength and oscillator strength of the dominating singlet transition, $X^{l} A_{1} \rightarrow 1^{1} B_{2}$, in $\frac{\text { chalcogenophene compounds. }}{\mathrm{HF} / 6-31 \mathrm{G}}$

\begin{tabular}{|c|c|c|c|c|c|c|c|c|c|c|}
\hline \multirow{2}{*}{ Compound } & \multicolumn{2}{|c|}{$\mathrm{HF} / 6-31 \mathrm{G}$} & \multicolumn{2}{|c|}{ B3LYP/6-31G } & \multicolumn{2}{|c|}{$\begin{array}{c}\text { B3LYP/ } \\
\text { cc-pVDZ }\end{array}$} & \multicolumn{2}{|c|}{$\begin{array}{l}\text { CAM-B3LYP/ } \\
\text { aug-cc-pVDZ }\end{array}$} & \multicolumn{2}{|c|}{ Experimental $^{\mathrm{a}}$} \\
\hline & $\begin{array}{c}\lambda_{\text {exc }} \\
(\mathrm{nm})\end{array}$ & $f$ & $\begin{array}{c}\lambda_{\operatorname{exc}} \\
(\mathrm{nm})\end{array}$ & $f$ & $\begin{array}{c}\lambda_{\text {exc }} \\
(\mathrm{nm})\end{array}$ & $f$ & $\lambda_{\text {exc }}(\mathrm{nm})$ & $f$ & $\begin{array}{l}\lambda_{\max } \\
(\mathrm{nm})\end{array}$ & $\begin{array}{c}\varepsilon / 10^{4} \text { at } \lambda_{\max } \\
\left(\mathrm{M}^{-1} \mathrm{~cm}^{-1}\right)\end{array}$ \\
\hline 01-Me & 313 & 1.50 & 370 & 1.67 & - & - & 349 & 1.69 & - & - \\
\hline O1-Pe & - & - & - & - & - & - & - & - & 338 & 5.1 \\
\hline S1 & 326 & 1.35 & 382 & 1.57 & 395 & 1.56 & 362 & 1.53 & 348 & 3.0 \\
\hline S1-Pe & - & - & - & - & - & - & - & - & $352^{b}$ & $3.5^{b}$ \\
\hline S1-OMe ${ }^{c}$ & 329 & 1.54 & 395 & 1.82 & 407 & 1.81 & 368 & 1.77 & 356 & 3.3 \\
\hline S1-NO2a & - & - & - & - & 447 & 1.70 & 389 & 2.60 & - & - \\
\hline S1-NO2b & 298 & 1.11 & 385 & 1.44 & - & - & 360 & 1.46 & - & - \\
\hline S1-NO2-Pe & - & - & - & - & - & - & - & - & 390 & 2.8 \\
\hline S1A-Pe & - & - & - & - & - & - & - & - & 314,358 & $4.2,2.6$ \\
\hline S2 & - & - & 449 & 3.06 & 467 & 3.08 & - & - & - & - \\
\hline S2-Pe & - & - & - & - & - & - & - & - & $380^{b}$ & $8.0^{b}$ \\
\hline S3 & - & - & 479 & 4.32 & - & - & - & - & - & - \\
\hline S3-Pe & - & - & - & - & - & - & - & - & $385^{b}$ & $13^{b}$ \\
\hline Se1 & 341 & 1.23 & 395 & 1.50 & 408 & 1.49 & 376 & 1.43 & 359 & 4.2 \\
\hline Se1-OMe & - & - & - & - & - & - & 383 & 1.66 & - & - \\
\hline Se1-NO2a & - & - & - & - & - & - & 407 & 2.05 & - & - \\
\hline Se2 & 381 & 2.38 & 462 & 3.02 & 480 & 3.04 & - & - & - & - \\
\hline Se3 & - & - & 491 & 4.26 & 512 & 4.32 & - & - & - & - \\
\hline Te1 & 353 & 1.15 & 407 & 1.44 & 420 & 1.43 & 389 & 1.36 & - & - \\
\hline Te1-OMe & - & - & - & - & - & - & 396 & 1.58 & - & - \\
\hline Te2 & 404 & 2.10 & 473 & 2.98 & 491 & 3.00 & - & - & - & - \\
\hline Te3 & - & - & 500 & 4.21 & 522 & 4.28 & - & - & - & - \\
\hline
\end{tabular}

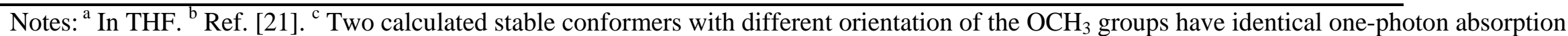
properties. 
Table 3. Dominating excited-state absorptions for $1^{1} B_{2} \rightarrow n^{1} A_{1}$ transitions in the region of 400-850 $\mathrm{nm}$. Results are obtained with use of the CAM-B3LYP functional and the aug-cc-pVDZ basis set (unless specified). Transitions with oscillation strength $\geq 0.02$ are reported.

\begin{tabular}{|c|c|c|}
\hline \multirow[t]{2}{*}{ Compound } & \multicolumn{2}{|c|}{ CAM-B3LYP/aug-cc-pVDZ } \\
\hline & $\lambda_{\mathrm{exc}}(\mathrm{nm})$ & $f^{1 \rightarrow n}$ \\
\hline \multirow[t]{3}{*}{ O1-Me } & 807 & 1.021 \\
\hline & 507 & 0.086 \\
\hline & 461 & 0.084 \\
\hline \multirow[t]{5}{*}{ S1 } & 788 & 0.702 \\
\hline & 709 & 0.377 \\
\hline & $788^{a}$ & $0.684^{\mathrm{a}}$ \\
\hline & $711^{\mathrm{a}}$ & $0.378^{\mathrm{a}}$ \\
\hline & $415^{\mathrm{a}}$ & $0.093^{\mathrm{a}}$ \\
\hline \multirow[t]{2}{*}{ S1-OMe } & 806 & 1.033 \\
\hline & 673 & 0.216 \\
\hline \multirow[t]{2}{*}{ S1-NO2b } & 805 & 0.641 \\
\hline & 684 & 0.302 \\
\hline \multirow[t]{2}{*}{ Se1 } & 842 & 0.04 \\
\hline & 748 & 1.02 \\
\hline \multirow[t]{2}{*}{ Te1 } & 749 & 0.075 \\
\hline & 735 & 0.946 \\
\hline Se1-OMe & 737 & 0.861 \\
\hline \multirow[t]{2}{*}{ Te1-OMe } & 825 & 0.042 \\
\hline & 725 & 0.921 \\
\hline
\end{tabular}

Note: ${ }^{a}$ Calculated with the daug-cc-pVDZ basis. 
Table 4. Optical power limiting and luminescence spectral data for chalcogenophenes in THF.

\begin{tabular}{|c|c|c|c|c|c|}
\hline Compound & $\begin{array}{l}E_{\text {out }}(\mu \mathrm{J}) \text { at } \\
E_{\text {in }} \text { of } 150 \mu \mathrm{J}, \\
532 \mathrm{~nm}^{\text {a }}\end{array}$ & $\lambda_{\mathrm{fl}}(\mathrm{nm})^{\mathrm{b}}$ & $\begin{array}{l}\text { Stokes shift } \\
(\mathrm{nm})^{\mathrm{c}}\end{array}$ & $Q_{\mathrm{fl}}$ & $\tau_{\mathrm{fl}}(\mathrm{ns})^{\mathrm{d}}$ \\
\hline O1-Pe & $20^{e}$ & (368), 388 & 30 & 0.07 & 0.08 \\
\hline S1 & 25 & $383,(403)^{f}$ & 35 & $0.16^{f}$ & \\
\hline S1-Pe & $23^{e}$ & $388,(405)$ & 36 & 0.18 & 0.22 \\
\hline S1-OMe & $18.5^{\mathrm{e}}$ & $394,(412)$ & 38 & 0.17 & $\begin{array}{l}0.24(88 \%) \\
0.06(12 \%)\end{array}$ \\
\hline S1-NO2-Pe & $13^{g}$ & $\begin{array}{l}400-430^{\mathrm{h}} \\
525-540^{\mathrm{f}, \mathrm{h}}\end{array}$ & $\begin{array}{l}\sim 10-40^{\mathrm{h}} \\
\sim 135-150^{\mathrm{f}, \mathrm{h}}\end{array}$ & $\begin{array}{l}<0.001^{\mathrm{h}} \\
<0.004^{\mathrm{f}, \mathrm{h}}\end{array}$ & $\begin{array}{l}6(67 \%)^{\mathrm{h}} \\
1(22 \%)^{\mathrm{h}} \\
0.1(11 \%)^{\mathrm{h}}\end{array}$ \\
\hline S1A-Pe & 20 & $\begin{array}{l}(368), 404, \\
(422)\end{array}$ & 46 & 0.09 & $\begin{array}{l}0.18(95 \%) \\
3.7(5 \%)\end{array}$ \\
\hline S2-Pe & $16^{\mathrm{i}}$ & 422, (444) & 42 & 0.41 & 0.39 \\
\hline S3-Pe & $14^{\mathrm{i}}$ & 431, (454) & 46 & 0.50 & 0.42 \\
\hline Se1 & $20^{\mathrm{e}}$ & 400 & 41 & $<0.001^{\mathrm{h}}$ & $\begin{array}{l}6(13 \%)^{h} \\
1(3 \%)^{h} \\
1-10 \cdot 10^{-3}(84 \%)^{h, j}\end{array}$ \\
\hline
\end{tabular}

Notes: ${ }^{a}$ Conc. 0.010 M. ${ }^{b}$ Conc. $\leq 2 \cdot 10^{-5}$ M. Excitation at $360 \mathrm{~nm}$ except for S1-OMe where this was $337 \mathrm{~nm}$. Values in parenthesis are for smaller peaks or shoulders of the main peak(s). ${ }^{\mathrm{c}}$ Difference between the lowest-energy and highest-energy peak in the absorption and emission spectrum, respectively. ${ }^{\mathrm{d}}$ Percentage values in parenthesis are for decays which were best fitted with a two- or three-component exponential function. ${ }^{\mathrm{e}}$ Ref. [20]. ${ }^{\mathrm{f}}$ Measured in $\mathrm{CHCl}_{3} .{ }^{\mathrm{g}}$ Measurements performed at a maximum of $120 \mu \mathrm{J}$ for $E_{\text {in }} E_{\text {out }}=13$ for $E_{\text {in }}=65-120 \mu \mathrm{J}$. ${ }^{\mathrm{h}}$ Uncertain because of very weak emission. ${ }^{\mathrm{i}}$ Ref. [21]. ${ }^{\mathrm{j}}$ Uncertain because of instrumental limitations in the ps region. 